ICEEPSY 2021

$12^{\text {th }}$ International Conference on Education \& Educational Psychology

\title{
STRESS CONCEPTUALIZING IN STUDENTS OF DIFFERENT CULTURES
}

\author{
Elena Volkova (a)*, Irina Kuvaeva (b) \\ *Corresponding author
}

(a) Institute of Psychology, Russian Academy of Science, Russia, volkovaev@mail.ru

(b) Department of Psychology, Ural Federal University, Russia, irina.kuvaeva@urfu.ru

\begin{abstract}
The first year of the university study is stressful for most students. In the context of open education, this problem is exacerbated, since the understanding of stress and how to cope with it among students of different cultures differ. There are studies on the differences in the perception of Stress between students of Eastern and Western cultures, individualistic and collectivist cultures. But the question arises whether there are differences in the Stress perception among students of the same cultural group. The goal of the study was to reveal the peculiarities of notions about Stress among Russians, Armenians, Tatars, Turks, and Chinese. More than 700 first-year university students were invited to participate in the study. Research methods included the analysis of dictionaries, directed associative experiment (Stimulus was word Stress), the pictographic technique (Stress image). The findings testified significant differences in the sensory, emotional, and temporal modalities of Stress perceptions among students of Eastern cultures (ANOVA, $p$ $=0.000$; multiple comparisons). The notions of Stress among Russian students are pronounced in sensory, emotional, and temporal modalities. The dominant emotional perception of Stress is characteristic of the Tatars. The Armenians and Chinese are distinguished by the severity of the spatial-temporal modality of Stress perception. The notions of Stress among Turkish freshmen are concrete and low-emotional. The data obtained are important to adapting the freshman and maintaining their psychological well-being.
\end{abstract}

2672-8141 @ 2021 Published by European Publisher.

Keywords: Stress, concept, Eastern cultures, freshmen 


\section{Introduction}

The first year of the university study is stressful for most students: life away from their parents, problems in their personal life, lack or excess of textbooks, high academic load, and everyday problems. According to Madaan et al. (2020), 43\% of freshmen have high stress, more than half (57\%) students report moderate stress. Iorga et al. (2018) point out that freshmen are the most depressed students. Exams increase student stress. It should be noted that stress is more pronounced in females, it manifests itself in fear and anger, a decrease in the quality of sleep (Garret et al., 2017). Stressful overload leads to failure, poor grades, and exhaustion in the freshman (Amirkhan \& Kofman 2018) and causes avoidance coping (Dyson \& Renk, 2006). In the context of open education, this problem is exacerbated many times over, since the understanding of stress and how to cope with it among students of different cultures differ.

Individual consciousness is mediated by the culture. People constantly exchange the results of their mental activity, due to which the results of the individuals's brain reflexive activity are accumulated over several generations (Chuprikova, 1985). Thus, culture acts as a unique informational and learning system shared by a group of people and passed down from generation to generation. Culture influences the mental processes and behavior of people (Matsumoto \& Juang, 2017). Triandis (1996) emphasizes the multidimensionality of culture. Cultural syndrome includes attitudes, beliefs, categorizations, norms, values, a certain historical period, geographical region, and language.

Culture has a dual nature, as Anolly (2016) notes, - "it is outside and inside the mind at the same time" (p. 37). Language and sign play a key role in the process of interiorization (the transition from the external to the internal world). Signs are stable meanings embedded in culture (Vygotsky, 1982). Language is a specific tool for transmitting information and implementing collective activities in culture (Aleksandrov \& Aleksandrova, 2009).

Cultural differences in stress representations and copings can be due to both objective (explicit) and subjective (implicit) elements of culture. Through social representations, the individual rediscover information about permitted and forbidden ways to achieve goals.

\section{Problem Statement}

Culture, as Hofstede (2011) wittily pointed out, is the collective programming of the mind that distinguishes the members of one group or category of people from others. Traditionally, cross-cultural research focuses on comparing Eastern and Western cultures, Individualist and Collectivist cultures. However, the question arises, are there any differences in psychological variables among representatives of Eastern culture? Our research is devoted to the study of the peculiarities of stress representations in Russians, Armenians, Tatars, Turks and Chinese, who traditionally belong to the Eastern culture.

A short literature review shows that the most pronounced manifestations of stress in Russian freshmen were affective and psychosomatic disorders, attention and sleep disorders. The predominant strategies for overcoming difficulties in freshmen were taking medicine, drinking alcohol, smoking, spending time in social networks, and playing computer games (Ruzhenkov et al., 2017).

There are few studies on stress manifestations among modern Armenian students. Psychologists study the consequences of the Ottoman Turkish Genocide (1915), which led to the destruction of family 
ties and the usual way of life (Kademian, 2016). Armenians avoid the word Past when describing themselves: it is associated with high anxiety and "refers to the Ottoman Turkish Genocide as an unresolved trauma" (Berberyan \& Berberyan, 2016, p. 134). Religious coping is a significant way to cope with stressful situations in Armenian culture (Kademian, 2016; Papazyan et al., 2016).

Exam stress causes increased tension in Turkish students (Bahadir - Yilumas, 2016; Bayram et al., 2014), which they manage through assertive behavior, optimistic perception of difficulties and withdrawal from social support (Bahadir - Yilumas, 2016). One fifth of students are depressed due to financial hardships and health problems (Arslan et al., 2019). 63\% of dental department freshman worry about failing the course or year due to the inability to finish clinical schoolwork and have the highest stress levels (Demicri et al., 2021).

A large cross-sectional multistage study covering 11954 students from 50 Chinese universities in 43 cities showed that the greater is the perceived uncertainty stress, the is higher the prevalence of mental disorders (Wu et al., 2020). Chinese students experience stress due to high competition, poor economic conditions of the family, combining study with work, difficulties in finding a job after graduation (Chen et al., 2009; Ji \& Zhang, 2011).

There is practically no research on the peculiarities of stress manifestation in Tatars.

\section{Research Questions}

Do notions of Stress vary in students of Eastern cultures?

\section{Purpose of the Study}

To study the peculiarities of notions about Stress among Russians, Armenians, Tatars, Turks, and Chinese.

\section{Research Methods}

The collection of empirical data was carried out in accordance with the Universal Declaration of Ethical Principles to Psychologists. The study was conducted in the native language of the respondents. Freshmen signed informed consent. The research was anonymous. Participants pointed out only their age, sex, ethnic and cultural affiliation.

\subsection{Participants}

The study sample consisted of 712 first-year university students (510 female/202 male) aged $19.2 \pm$ 2.0 (329 Russians, 153 Armenians, 73 Tatars, 72 Turks, and 77 Chinese).

\subsection{Measures}

Research methods included the analysis of dictionaries, directed associative experiment (Stimulus was word Stress), the pictographic technique (Stress image). 
The analysis of dictionaries indicates the features of stress in the Russian, Armenian, Tatar, Turkish, and Chinese cultures.

Directed associative experiment identifies the implicit representations about the Stress and sensory, emotional, and temporal modalities of the concept Stress in different cultures. Participants are instructed to write as many adjectives as possible on the stimulus word Stress (The test time is limited to three minutes) and to draw images of Stress (The test time is limited to two minutes). The Russians, Armenians and Tatars applied the adjectives and participles, the Turks and Chinese - the nouns. The images are differed in content and number of details.

Qualitative data processing is related to the comparison of the linguistic and psychological interpretations of stress. The modalities demonstrate the sensory, emotional, and temporal attributes of stress conceptualizing.

Statistical treatment included Descriptive Statistics (Frequency, Skewness, Kurtosis), Compare Mean Statistics (One-Way ANOVA, Factor - cultural group, dependent variables - the notions of stress).

\section{Findings}

\subsection{Linguistic interpretation of Stress in Eastern cultures}

The definitions of Stress, represented in Russian, Armenian, Tatar, Turkish, and Chinese dictionaries, are shown in Table 1. The common attribute of Stress is a Tension. Such peculiarity of Stress as the nervous state is specified in Russian, Tatar, and Turkish dictionaries. It should be noted that the word Stress in Armenian is represented only in specialized medical and psychological dictionaries.

Table 1. The attributes of Stress in Russian, Armenian, Tatar, Turkish and Chinese dictionaries

\begin{tabular}{ll}
\hline Languages & Attributes of stress \\
\hline Russian & Tense, intense, nervous, anxious, negative, active \\
Armenian & Tense, pressing, anxious, problem-focused \\
Tatar & Tense, nervous, complex \\
Turkish & Tense situation, oppressive state, nervousness, anxious \\
Chinese & Tense, excited, pressing, social action, problem-focused, ready to act, difficult \\
\hline
\end{tabular}

\subsection{Perception of Stress among students of Eastern cultures}

The dynamics aspects of stressful situations are important to students of four cultural groups: duration of stress is important for the Russians and Armenians; the speed and suddenness of a stressful situation are essential for the Tatars and the Chinese. A strongly pronounced focus on economic and financial success provokes a stressful situation in the Turks.

The summary results of the analysis of the peculiarities of the Stress perception in freshman of the above-described cultures are presented in Table 2. 
Table 2. The peculiarities of the Stress perception in freshman of Eastern cultures

\begin{tabular}{|c|c|c|}
\hline $\begin{array}{l}\text { Cultural } \\
\text { groups }\end{array}$ & $\begin{array}{l}\text { Typical verbal reactions } \\
\text { to stimulus STRESS }\end{array}$ & $\begin{array}{l}\text { Typical images } \\
\text { of Stress }\end{array}$ \\
\hline Russians & $\begin{array}{l}\text { Nervous, tense, exhausted, exiting, severe, } \\
\text { negative, sad, heavy, depressed, prolonged }\end{array}$ & $\begin{array}{l}\text { Different stressful situation, physiological } \\
\text { symptoms, psychological manifestations, non- } \\
\text { constructive coping strategies }\end{array}$ \\
\hline Armenians & Nervous, tense, psychological, prolonged & $\begin{array}{l}\text { War, death, funeral, poverty, symptoms of } \\
\text { stress, a broken heart }\end{array}$ \\
\hline Tatars & $\begin{array}{l}\text { Nervous, sad, terrible, disturbing, } \\
\text { instantaneous, unexpected }\end{array}$ & $\begin{array}{l}\text { Everyday difficulties, negative emotions, } \\
\text { isolation }\end{array}$ \\
\hline Turks & Exam, tense, work, anxious, intrusive & Desktop, textbook, KPSS-exam, money \\
\hline Chinese & Tense, terrible, pressing, active, fast & $\begin{array}{l}\text { Chaos, a twisted towel, water, air, flame, tree, } \\
\text { sun, stone, spiral }\end{array}$ \\
\hline
\end{tabular}

The Armenians conceptualize global traumatic events and a broken heart as a symbol of grief and loss. The Russians notes the variety of stress manifestations and the ways to overcome it. The Armenians and Russians describe the stressful situations as nervous, tense, and prolonged. Their notions of stress are highly differentiated and detailed.

Such an attribute of stress as nervous is important for the Tatars. Their representations of Stress are very diverse, but little detailed. They describe everyday problems, negative emotions, and brightly depicted the wall and the barriers.

Turks point out the exam tension and anxiety for their future work. Their images of Stress are uniform and low detailed. They depict the attributes of the student's educational activities, abbreviations for examinations, and signs of a successful life in Turkish society (money, car, house).

The notions of stress among the Chinese are symbolic and metaphorical. They draw the spiral, which is associated with a chaos, and a twisted towel that is concerned with the tension.

\subsection{The sensory, emotional, and temporal attributes of stress conceptualizing}

Figure 1 demonstrates significant differences in modalities of stress perceptions among students of Eastern cultures (ANOVA, $\mathrm{p}=0.000$; multiple comparisons). The notions of Stress among Russian students are pronounced in sensory, emotional, and temporal modalities. The Armenians conceptualized the stressful situations predominantly in the sensory and temporal modalities (nervous, tense, and prolonged). Stress conceptualizing among Tatars is characterized the dominant emotional modality, they described a lot of negative emotions concerning the stressful situation. The Turks and the Chinese indicate the sensory and temporal modality; they described the emotional attributes less frequently.

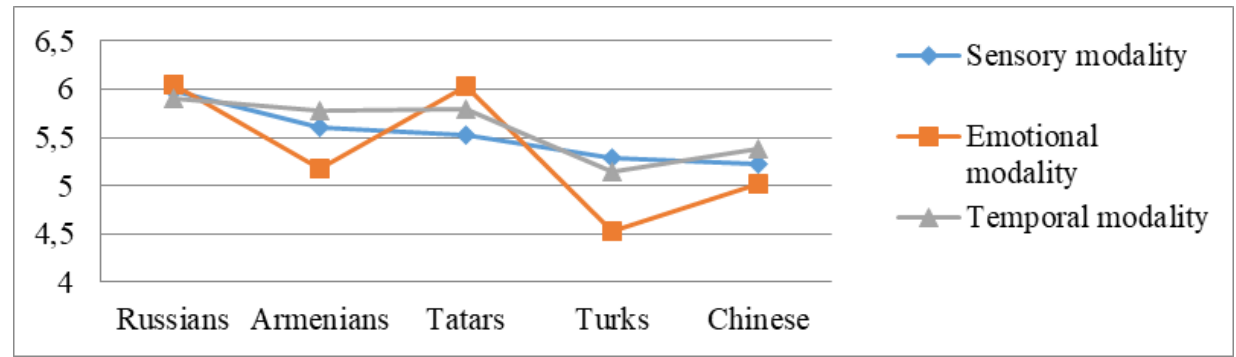

Figure 1. The manifestations of sensory, emotional, and temporal modalities of Stress in Eastern cultures 


\section{Conclusion}

The cultural context defines both a common and a different understanding of stress by students of Eastern cultures. The word Stress in Russian, Armenian, Tatar, Turkish, and Chinese languages interpret as tension. The general psychological understanding of Stress among students of Eastern cultures is Tension (except Tatars). However, the notions about stress in students of Eastern cultures differs. The notions of stress among Russians and Armenians are highly differentiated and detailed, among the Chinese are symbolic and metaphorical, among the Turks are concrete, among the Tatars are highly variative but lowdetailed.

Teaching students in open education requires taking into account the peculiarities of behavior in stressful situations among students of different cultures. Namely, Chinese students need to be together and realize social action in stressful situations. The Turkish students feel calm and confident in the case they are aware about procedure of exam and criteria of assessment. Russian, Tatar and Armenian students should have access to psychological counselling and training in effective coping strategies.

\section{References}

Aleksandrov, U. I., \& Aleksandrova, N.L. (2009). Syb'ektibniy opit, kyltyra i social'nie predstavleniya [Subjective experience, culture, and social representations]. Publishing House "Institute of Psychology, RAS” (In Russian).

Amirkhan, J., \& Kofman, Y. B. (2018). Stress overload as red flag for freshman failure and attrition. Contemporary Educational Psychology, 297-308. https://doi.org/10.1016/j.cedpsych.2018.07.004

Anolly, L. (2016). Psihologiya kul'turi [Psicologia della cultura]. Publishing House «Humanitarian Center» (In Russian).

Arslan, G., Auranci, U., Unsal, A., \& Arslantas, D. (2019). Prevalence of depression, its correlates among students, and its effect on health-related quality of life in a Turkish university. Upsala Journal of Medical Sciences, 144, 170 - 177. http://doi.org/10.1080/03009730903174339

Bahadir-Yilumas, E. (2016). Academic and clinical stress, stress recourses and ways of coping among Turkish first-year nursing students in their first clinical practice. KONTAKT, 18, 145-151. https://doi.org/10.1016/j.kontakt.2016.08.001

Bayram, N., Dogan, A., Aydogan, I., \& Bilgel, N. (2014). Anger Expression, Depression, Anxiety and Stress among Turkish Students Living in Turkey and Germany. Internat. J. of Academic Research and Social Sciences, 4(3), 1-18. https://doi.org/10.6007/IJARBSS/v4-i3/669

Berberyan, A. S., \& Berberyan, H. S. (2016). Ethnopsychological aspects of the meaning-of-life and value orientations of Armenian and Russian students. Psychology in Russia: State of the Art, 9(1), $121-$ 137. http://doi.org/11621/pir.2016.0109

Chen, H., Wong, Y-C., Ran, M-S., \& Gilson, C. (2009). Stress among Shanghai University Students. Journal of Social Work, 9(3), 323-344. http://doi.org/10.1177/1468017309334845

Chuprikova, N. I. (1985). Psihika i soznanie kak funksiaya mozga [Psyche and consciousness as a function of the brain]. Publishing House "Science" (In Russian).

Demicri, M., Tekce, N., Cobanoglu, N., Tuncer, S., Unlu, O., Sismanoglu, S., \& Baydemir, C. (2021). Perceived Sources and Levels of Stress Among Turkish Dental Students: A Multi-centre Study. BEZMIALEM SCIENCE, 9(3), 271-282. http://doi.org/10.14235/bas.galenos.2020.4409

Dyson, R., \& Renk, K. (2006) Freshman Adaptation to University Life: Depressive Symptoms, Stress and Coping. Journal of Clinical Psychology, 62(10), 1231-1244. https://doi.org/10.1002/jclp.20295 
Garret, R., Liu, S., \& Young, S. D. (2017). A longitudinal analysis of stress among incoming college freshmen. Journal of American College Health, 65, 331-338. http://doi.org/10.1080/07448481.2017.1312413

Hofstede, G. (2011). Dimensionalizing cultures: The Hofstede model in context. Online Readings in Psychology and Culture, 2(1), 1-26. https://doi.org/10.9707/2307-0919.1014

Ji, H., \& Zhang, L. (2011). Research on college students' stresses and coping strategies. Asian Social Sci, 7(10), 30-34. https://doi.org/10.5539/ass.v7n10p30

Iorga, M, Dondas, C., \& Zugun-Eloae, C. (2018). Depressed as Freshmen, Stressed as Seniors: The Relationship between Depression, Perceived Stress and Academic Results among Medical Students. Behavioral Sciences, 8(8), 70. https://doi.org/10.3390/bs8080070

Kademian, F. I. (2016). The relationships among immigration stress, Armenian ethic identity, and posttraumatic growth [Doctoral Dissertation, Alliant International University]. ProQuest Dissertations Publishing, 2017. 10248516. Los Angeles.

Madaan, N., Wundavallim L., \& Satapathy, S. (2020). Techno stress among medical freshmen: An exploratory study. J Edu Health Promotion, 9, 178. http://doi.org /10.4103/jehp.jehp_242_19

Matsumoto, D., \& Juang, L. (2017). Culture and Psychology (Sixth Edition). Cengage Learning.

Papazyan, A., Bui, N., \& Der-Karabetian, A. (2016). Life satisfaction, Acculturative Stress, Ethic Identity, and Gender Role Attitudes among Armenian American Women. American Journal of Contemporary Research, 6(1), 10-21.

Ruzhenkov, V. A., Ruzhenkova, V. V., Lukyantseva, I. S., Boeva, A. V., \& Moskvitina, U. S. (2017). Academical Stress for the First and Second Year Medical Students and Possible Risks to Mental Health. International Journal of Advanced biotechnology and research, 8(4), 2218-2225.

Triandis, H. C. (1996). The psychological measurement of cultural syndrome. American Psychologist, 51(4), 407 - 415. http://doi.org/10.1037/0003-066X.51.4.407

Vygotsky, L. S. (1982). Thinking and communication. In Collected Works of L. S. Vygotsky (pp. 5-361). Pedagogika (In Russian).

Wu, D., Yu, L. W., Yang, T. Z., Cottrell, R., Peng, S. H., Guo, W., \& Jiang, S. H. (2020). The Impacts of Uncertainty Stress on Mental Disorders of Chinese College Students: Evidence From a Nationwide Study. Frontiers In Psychology, 11(243), 1-9. https://doi.org/10.3389/fpsyg.2020.00243 